Int. J. Electrochem. Sci., 11 (2016) 9868 - 9880

\title{
Simultaneous Determination of $m$-Trihydroxybenzene and $p$ - Nitrophenol at Glassy Carbon Electrode Modified with Graphene Oxide
}

\author{
Hongying Lit ${ }^{1,2}$, Xueliang Wang ${ }^{2}$, Tao Wang ${ }^{2}$, Zhaoxia Wang $^{2}$, Wei Zhao, ${ }^{1, *}$ \\ ${ }^{1}$ School of Chemical Engineering, China University of Mining and Technology, Xuzhou, 221116, \\ Jiangsu, P.R.China. \\ ${ }^{2}$ Department of Chemistry and Chemical Engineering, Heze University, Heze, 274015, Shandong, P. \\ R. China. \\ *E-mail: hxxlhy@163.com
}

doi: $10.20964 / 2016.12 .09$

Received: 21 August 2016 / Accepted: 28 September 2016 / Published: 10 November 2016

\begin{abstract}
A modified electrode was fabricated by casting graphene oxide (GO) suspension onto the surface of active glassy carbon electrode (GCE), and it can significantly enhanced the oxidation peak currents of m-trihydroxybenzene (m-THB) and p-nitrophenol (p-NP). Based on this, a sensitive analytical method towards their simultaneous determination was established. Many influencing factors such as the type of electrolyte, acidity, scan rates and concentrations were explored. Under the optimal experimental conditions, the oxidation peak currents of $\mathrm{m}-\mathrm{THB}$ and $\mathrm{p}-\mathrm{NP}$ were linearly increased with their concentrations ranging from 9 to $100 \mu \mathrm{M}$, with the detection limits both of $1 \mu \mathrm{M}$. Comparing with other reported methods, this sensor showed wider linear range and lower detection limit. In addition, the proposed method was successfully used to analysis of real environmental water samples with satisfactory recoveries, which verified the practicability of the sensor.
\end{abstract}

Keywords: m-trihydroxybenzene, p-nitrophenol, graphene oxide, modified electrode

\section{FULL TEXT}

(C) 2016 The Authors. Published by ESG (www.electrochemsci.org). This article is an open access article distributed under the terms and conditions of the Creative Commons Attribution license (http://creativecommons.org/licenses/by/4.0/). 